\title{
Partition of the Human Cerebellum in Sensory-Motor Activities, Learning and Cognition
}

\author{
P.E. Roland
}

\begin{abstract}
The circuitry of the cerebellum is quite well understood. The computation takes place in the cerebellar cortex, which functions in synchronized strips to provide excellent timing signals to the cerebral cortex and the spinal cord. The cerebellar cortex is also the site where error signals from other parts of the central nervous system are incorporated. For voluntary limb movements the cerebellular cortex is important for the timing of the innervation of the agonist and antagonist anterior horn neurons. It is also important for the temporal order of and precision in the execution of motor programs. As will be apparent, the cerebellum is not only a computer taking care of motor programs.

RÉSUMÉ: Répartition dans le cervelet des activités sensitivomotrices, d'apprentissage et de cognition. Des études récentes du cervelet humain au moyen de traceurs ont révélé que le cervelet n'est pas impliqué seulement dans des activités sensitivomotrices localisées principalement dans le lobe antérieur, mais aussi dans des activités motrices non sensitives. Ces dernières sont actuellement classées comme étant cognitives. Les activités cognitives et les modifications des activités sensitivomotrices dues à l'apprentissage semblent se produire principalement dans le lobe postérieur.
\end{abstract}

Can. J. Neurol. Sci. 1993; 20 (Suppl. 3): S75-S77

The output from the Purkinje cells goes to the cerebellar nuclei deep in the cerebellum. Humans have four nuclei, of which the dentate is the most recently developed and by far the largest. The human dentate nucleus consists of a phylogenetically older part, the magnocellular portion and phylogenetically recent part the parvocellular part. ${ }^{4}$ The axons intervating the dentate nucleus comes from the lateral part of the cerebellar hemispheres. A smaller intermediate zone send axons to the small globose and emboliform nuclei and the midzone, vermis, sends axons to the fastigial nucleus.

The afferents from the motor cortex and the somatosensory cortex plus the afferents from the spinal cord are somatotopically organized. The cerebellar computation does not disturb this somatotopy. Recordings from single neurons in the dentate nucleus have shown that the dentate neurons to $50 \%$ discharge before the start of voluntary movements and that $2 / 3$ of the neurons which are movements related also fire to sensory stimuli, i.e., a light tone or stretch of a muscle in a reaction time paradigm. Only $1 / 5$ of the movement related neurons fire exclusively related to movements. ${ }^{5}$

The efferents from the magnocellular portion of the dentate nucleus go to the red nucleus. The efferents from the parvocellu- lar portion goes to the VLa, VLp and VPL nuclei of thalamus. ${ }^{6}$ From here the cerebellar output reaches the cerebral cortex. The output from the globose nucleus reaches the Darkschevitch nucleus in the higher brain stem, and that from the emboliform nucleus reaches the CM intralaminar nucleus of thalamus. ${ }^{6}$ The fastigial nucleus is related to centers for eye movements (superior colliculus) and the spinal cord and lower brainstem.

From this, one would expect the human cerebellum to be engaged in sensory-motor tasks, but also in generation and control of eye movements. Table 1 shows the tasks giving rise to increases in regional cerebral blood flow (rCBF) or regional cerebral metabolism (rCMR) in the cerebellum. So far nobody has reported decreases in rCMR or rCBF. The tasks comprise motor tasks, sensory-motor tasks, but also and perhaps unexpectedly, purely cognitive tasks and thinking.

\section{The Anterior Lobe of Cerebellum}

Voluntary movements of the fingers or the hand, either as part of a motor paradigm or as part of a somatosensory exploration of objects increase rCBF and rCMR in the lateral part of the anterior lobe of cerebellum (Table 1). $\mathrm{Ca}^{2+}$ channel studies in man revealed the neurons depolarize here during the task. ${ }^{7}$

From the Laboratory of Brain Research and Positron Emission Tomography, Karolinska Institute, Stockholm, Sweden

Reprint requests to: Dr. P.E. Roland, Laboratory of Brain Research and Positron Emission Tomography, Karolinska Institute, S10401, Stockholm, Sweden 
Table 1: Tasks Which Produced Changes in rCBF and rCMR in the Cerebellum

\begin{tabular}{|c|c|c|c|}
\hline Task & Site & Side & Authors \\
\hline Vibration & LAL & I & Fox et al. $1985 \mathrm{c}^{8}$ \\
\hline Flex-ext hand & LAL & I & idem \\
\hline Finger sequence & LAL & 1 & Fox et al. $1985 b^{14}$ \\
\hline Saccades no target & V & & idem \\
\hline Motor sequence & LAL & I & Seitz et al. $1990^{\circ}$ \\
\hline $\begin{array}{l}\text { Motor sequence } \\
\text { learning }\end{array}$ & LAL & I & idem \\
\hline Tactile learning & $\begin{array}{l}\text { LAL } \\
\text { LPL }\end{array}$ & $\begin{array}{l}\text { I } \\
\mathrm{B}\end{array}$ & $\begin{array}{l}\text { Roland et al. } 1987^{15} \\
\text { idem }\end{array}$ \\
\hline Tactile recognition & LAL & I & Roland et al. $1991^{16}$ \\
\hline Somatosensory discrim & LAL & I & Seitz et al. $1991^{10}$ \\
\hline - & LPL & B & idem \\
\hline - & Dentate & I & idem \\
\hline $\begin{array}{l}\text { Preparation for } \\
\text { reaching }\end{array}$ & LAL & B & Decety et al. $1992^{17}$ \\
\hline Route finding & LPL & B & Roland et al. $1987^{15}$ \\
\hline $\begin{array}{l}\text { Social philosophical } \\
\text { speech }\end{array}$ & & $\mathbf{R}$ & Pawlik et al. $1987^{13}$ \\
\hline $\begin{array}{l}\text { Repeating words shown } \\
\text { Word association }\end{array}$ & $\begin{array}{l}\text { VLA, LAL } \\
\text { VLA }\end{array}$ & . $R$ & $\begin{array}{l}\text { Raichle } 1990^{12} \\
\text { idem }\end{array}$ \\
\hline & LPL & B & idem \\
\hline Visual discrimination & VLA & & Gulyás et al. $1991^{18}$ \\
\hline Spontaneous speech & LA & $\mathrm{B}$ & Heiss et al. $1990^{19}$ \\
\hline
\end{tabular}

Fox et al. ${ }^{8}$ showed that it was the exact same site of the anterior lobe which increased $\mathrm{rCBF}$ when the hand was moved and when it was vibrated. Another way to illustrate the overlapping somatotopical arrangement of the somatosensory and somatomotor afferents to the anterior lobe is to subtract the activation caused by the performance of the motor sequence test ${ }^{9}$ from that of somatosensory discriminations of shape. ${ }^{10}$ By such a subtraction the activation of the anterior lobe cancels out. ${ }^{10}$

The rCBF and rCMR changes here are not related to the frequency of movements, at least not during learning. During learning of a motor task, the cerebellar changes were restricted to the anterior lobule. The rCBF remained unchanged despite a doubling of the frequency of finger movements during the course of learning. ${ }^{9}$ Thus there was a higher relative metabolic cost per finger movement in the early phase of learning.

Still within the anterior lobule of cerebellum, but localized to the vermis is the spot activated when the eyes are moving. One might think that the cerebellar increases in visual discrimination and route finding with the eyes closed were due to a higher frequency of eye movements during the tasks, but the frequency of eye movements did not increase from the control state in these tasks. So the vermis activation cannot be explained by eye movement frequency only.

\section{The Posterior Lobe of Cerebellum}

The lateral part of the posterior lobe is a rather large area and undoubtedly it consists of many different functional fields. Tactile learning increases the $\mathrm{rCMR}$ and $\mathrm{rCBF}$ in the posterior lobule. This increase is not due to learning of the exploratory finger movements, since these movements are not changed in the adults." The same fields are activated also when subjects discriminate the shapes of rectangular paralellepipeda, but in this case the rCBF or rCMR does not undergo any modulation. ${ }^{10}$ Thus the modulation of the initially large rCBF and rCMR increase is related to the learning of the sensory information. There is no such modulation of posterior lobe rCBF in visual learning. That the posterior lobe of cerebellum participated in learning is not surprising, but that it participates in learning of somatosensory information was unexpected.

Even more unexpected were several consistent studies showing that the posterior lobule participates in cognitive activities such as thinking ${ }^{15}$ and verbal encoding. The cortical parts activated seem to be more lateral than those engaged in tactile learning and somatosensory discrimination. ${ }^{10,11}$ The engagement of cerebellum in language is not related to the formation of the motor programs for speech. This is evident from the fact that word association, but not word repetition activates the posterior lobule (reference ${ }^{12}$ and Table 1). In the study of subjects speaking about a social philosophical subject ${ }^{13}$ it was only stated that the cerebellum is activated, but not which part was active.

This engagement of cerebellum in cognition was already pointed out in a few studies of patients with lesions of the posterior lobes. ${ }^{14}$ Saskai also reports a patient who could not keep the target of his intended action in mind after a cerebellar lesion. ${ }^{20}$

\section{Functional Cerebellar Sectors}

Although traditionally regarded as a motor structure, the cerebellar cortex is activated by not only motor tasks, but also in sensory tasks and situations in which the brain activity is neither sensory nor motor - that is during pure cognitive activity. The PET method provides accurate localization of the cerebellar cortical sectors which are engaged in these different sensory, motor and cognitive tasks. Like the basal ganglia the cerebellum is another example of a subcortical structure parcellated into motor, sensory-motor and cognitive sectors most likely defined by the cerebral cortical inputs the cerebellar cortex receive. However since the borders between the intermediate zone and the lateral zones are not revealed in the living human cerebellum, it is at present only possible to relate the activations to the gross anatomy of the cerebellum. Consequently, the activation can only be allocated to either vermis or the lateral zones of the anterior and posterior lobule.

\section{REFERENCES}

1. Ito M. The Cerebellum and Neural Control. New York: Raven Press 1984.

2. Smith AM. Comparing Cerebellar and Motor Cortical Activity in Reaching and Grasping. Can J Neurol Sci 1993: 20 (suppl.).

3. Bloedel JR. Real Time Operations of the Cerebellar Cortex. Can J Neurol Sci 1993: 20 (Suppl. 3), S7-S18.

4. Demole V. Structure et connexions des Noyaux dentelés du Cervelet. Swiss Arch Neurol Psychiat 1927; 271: 293-315.

5. Chapman CE, Spidalieri G, Lamarre Y. Activity of dentate neurons during arm movements triggered by visual, auditory and somesthetic stimuli in the monkey. J Neurophysiol 1986; 55: 203-226.

6. Hassler R. Über Kleinhirnprojektionen zum Mittelhirn und Thalamus beim Menschen. Deutsche Zeitschrift f. Nervenheilkunde 1950; 163: 629-671.

7. Roland PE, Seitz RJ. The functional anatomy of a single brain function: somatosensory discrimination of shape. In: Franzén $\mathrm{O}$, Westman F. Somatosensory Mechanisms. MacMillan 1990: 184194. 
8. Fox PT, Raichle ME, Thach WT. Functional mapping of the human cerebellum with positron emission tomography. Proc Natl Acad Sci USA 1985c; 82: 7462-7466.

9. Seitz RJ, Roland PE, Bohm C, Greitz T, Stone-Elander S. Motor learning in man: a positron emission tomographic study. NeuroReport 1990; 1: 17-20.

10. Seitz RJ, Roland PE, Bohm C, Greitz T, Stone-Elander S. Somatosensory discrimination of shape: tactile exploration and cerebral activation. Eur J Neurosci 1991; 3: 481-492.

11. Roland PE, Eriksson L, Widén L, Stone-Elander S. Changes in regional cerebral oxidative metabolism induced by tactile learning and recognition in man. Eur $\mathrm{J}$ Neurosci 1989; 1: 3-19.

12. Raichle ME. Exploring the mind with dynamic imaging. Seminars in the Neurosciences 1990; 2: 307-315.

13. Pawlik G, Heiss W-D, Beil C, et al. Three-dimensional patterns of speech-induced cerebral and cerebellar activation in healthy volunteers and in aphasic stroke patients studied by positron emission tomography of 2(18F)-fluorodeoxyglucose. In: Meyer JS, Lechner H, Reivich M, Ott EO, eds. Cerebral Vascular Disease 6. Amsterdam, New York, Oxford: Excerpta Medica 1987; 207210.

14. Leiner HC, Leiner AA, Dow RS. Does the cerebellum contribute to mental skills? Behavioral Neurosci 1986; 100: 443-454.
15. Roland PE, Eriksson L, Stone-Elander S, Widén L. Does mental activity change the oxidative metabolism of the brain? J Neurosci 1987; 7: 2373-2389.

16. Fox PT, Fox JM, Raichle ME, Burde RM. The role of cerebral cortex in the generation of voluntary saccades: a positron emission tomographic study. J Neurophysiol 1985b; 54: 348-369.

17. Decety J, Roland PE, Gulyás B. A PET study of the structures in the human brain engaged in the preparation phase of reaching. Neuro Report 1992; 3: 761-764.

18. Gulyás B, Roland PE. Cortical fields participating in form and color discrimination in the human brain. NeuroReport 1991; 2: 585-588.

19. Heiss WD, Pawlik G, Kessler J. Metabolic activation of the brain by speech and visual recognition. In: Ingvar DH, Lassen NA, Raichle ME, Friberg L, eds. Brain Work II, Munksgaard, Copenhagen: 1991; 334-343.

20. Sasaki K. Cerebro-cerebellar interconnections in cats and monkeys. In: Massion J, Sasaki K, eds. Cerebro-Cerebellar Interactions. Amsterdam: Elsevier/North-Holland Biomedical Press 1979; 105-124. 